\title{
LA POBREZA EN LA IX REGIÓN. REFLEXIONES DESDE LA DOCTRINA SOCIAL DE LA IGLESIA
}

Luis Martinez S.

En el marco de las Semanas Sociales 2001 de la diócesis de Temuco que pretendian reflexionar sobre el qué hacer de los cristianos frente a la pobreza de la IX Región, se me pidió presentar algunos minimos de Doctrina Social de la Iglesia que pudieran servir de horizonte para el compromiso de los cristianos con la transformación de la situación actual de marginación en que viven un gran número de nuestros hermanos. Mi exposición estuvo articulada en torno a dos momentos: el primero, un vistazo al contexto regional y el segundo, una invitación fraterna al compromiso con la justicia, por supuesto, todo esto en líneas bastante generales, pues se trataba de abrir el debate en torno a la cuestion más que de dar recetas de solución. De hecho, aunque quisiera ser más optimista, en honradez con la realidad actual, creo que las soluciones no son ni fáciles ni inmediatas.

\section{A. LA POBREZA EN LA IX Región.}

En el actual contexto global de las naciones, Chile aparece como un "modelo" de desarrollo politico y económico para los paises del llamado Tercer Mundo. El último informe sobre Desarrollo Humano del Programa de las Naciones Unidas para el Desarrollo (PNUD 2000) situó a nuestro país a la vanguardia del continente, en el lugar 34 del concierto de las naciones. Esto se debe fundamentalmente a que después de un período de crecimiento constante durante buena parte de los últimos 12 años, con tasas de crecimiento bordeando el $7,5 \%$ anual y un nivel de desempleo alrededor del $6 \%$, se ha logrado, caso único en Latinoamérica, reducir en más de un $50 \%$ el número de pobres'. En efecto, del $44,6 \%$ del año 1986 bajó al 20,6\% en la actualidad. 
Sin embargo, los últimos resultados de la encuesta de Caracterización Socioeconómica Nacional (CASEN) han revelado, que si bien la disminución de la pobreza a nivel nacional se mantiene en un ritmo constante, ella se da en la actualidad con un dinamismo inferior al de los años 1990-1996. Si en el año 1990 la población en condiciones de pobreza ascendia al $38.6 \%$ de la población nacional. en el año 1996 ella alcanzaba sólo al 23,2\%, es decir, 15.4 puntos menos. Sin embargo, en el periodo 1996-2000 la reducción fue tan sólo de 2,6 puntos pocentuales. En cuanto a la población en condiciones de indigencia, el fenómeno es aún más notable; se pasó de $12,9 \%$ el año 1990 a $5,7 \%$ el año 1996 (7,2 puntos menos); pero entre el año 1996 y el 2000 no se produjo variación en el porcentaje.

En concreto, en la actualidad en nuestro pais 3.081 .100 chilenos viven en condiciones de pobreza, y de ellos 850.000 se encuentran en situación de indigencia, es decir, 850.000 compatriotas a duras penas sobreviven en condiciones de vida infrahumanas. Resulta interesante remarcar que del total nacional de pobres $2.576 .200(83,6 \%)$ viven en sectores urbanos y que sólo $504.900(16,4 \%)$ viven en sectores rurales.

En la IX Región el $32,7 \%$ de la población, o sea, uno de cada tres personas, vive en condiciones de pobreza o indigencia. En cifras esto equivale a 276.247 personas viviendo en condiciones de pobreza y a 93.560 haciéndolo en condiciones de infrahumanidad o indigencia. En concreto, la IX región aporta a nivel nacional con un $9 \%$ del total de pobres, siendo las regiones Metropolitana y VIII quienes aportan con el mayor número, el $31,5 \%$ ( 970.200 personas) y el $16,8 \%$ (517.440 personas) respectivamente, es decir con un número cercano al millón y medio de pobres $(48,3 \%$ del total).

Otro dato significativo sobre la pobreza en la IX Región es tomar en cuenta que según el indice de Desarrollo Humano del PNUD, 12 de las 31 comunas regionales se encuentran ranqueadas en los últimos lugares entre las 333 comunas a nivel nacional (Purén 301, Lonquimay 305, Teodoro Schmidt 306, Galvarino 309, Freire 312, Renaico 315, Puerto Saavedra 318 , Nueva Imperial 320, Carahue 321, Lumaco 330, Melipeuco 326, Vilcún 329). En ranking por ingresos casi el $50 \%$ de la población regional laboralmente activa reciben un salario inferior a $\$ 150.000$. Nueva Imperial se encuentra en el último lugar, antecedida por Vilcún en el lugar 332, Carahue en el lugar 330 y Lumaco en el 329. En definitiva, de las 31 comunas de la Región, 15 tienen más del $40 \%$ de su población en condiciones de pobreza, muy lejos de ta media nacional que es de $20,6 \%{ }^{2}$

Otro dato que pucde resultar significalivo es el indice de escolaridad: la media nacimal alcanza 9,7 años, sin embargo en la Región disminuye a 8.7 años, y en comunas como Nueva Imperial la media alcanza sólo 6,8 años. De igual modo la tasa de analfabetismo, que a nivel nacional es de sólo un $4.6 \%$, en la Region sube a $7.9 \%$ y enl Nueva impcrial alcanza el $13.5 \%$. 
Un último dato al que quisiera referirme es a la presencia mapuche en nuestra Región (26\% de la población regional, es decir, alrededor de 230.000 personas. Resulta significativo que las comunas más pobres a las que nos hemos referido, sean todas de fuerte presencia Mapuche, los que podrian ser considerados según el decir de Puebla como "los más pobres entre los pobres". Ellos han sido sometidos a un proceso de empobrecimiento, de marginación y de discriminación desde los comienzos de la República. La pobreza que los aflige no les es esencial como pueblo como algunos lo piensan-, sino que es producto de la negación de su existencia como pueblo con identidad y cultura propias, y de la aplicación de sistemas productivos y de modelos de desarrollo que les son ajenos. En concreto, la pobreza en que se encuentra el pueblo mapuche se explica principalmente por la pérdida territorial que han sufrido en los últimos 130 años.

$\mathrm{Y}$, por lo mismo, los actuales conflictos tienen un antecedente histórico de largo tiempo que los ha llevado a la pobreza y marginación. Un hecho especialmente reprobable y que se encuentra a la base de los actuales conflictos fue lo ocurrido hace un cuarto de siglo, con la asi llamado "contra reforma agraria" que permitió la implantación y desarrollo de las empresas forestales en la Región cuyas utilidades a nivel nacional en el año 2000 alcanzaron la no pequeña suma de $\$ 686.497 .700 .000$.

Este último dato es de no poca relevancia. En los últimos tres años venimos escuchando hablar de una crisis económica: cesantia cercana al $10 \%$ y un crecimiento al 3 o $4 \%$ anual. Sin embargo, tal crisis económica no nos ha afectado a todos por igual, la realidad nos muestra lo contrario: "los ricos son cada dia más ricos". En efecto, la distribución de la riqueza nacional continúa en un proceso de concentración en los sectores más ricos: el $20 \%$ más rico captó el $57,3 \%$ del ingreso nacional y el $20 \%$ más pobre sólo tuvo acceso al $3,7 \%^{3}$. Sólo durante el año 2000 , las principales sociedades anónimas en Chile aumentaron sus utilidades en un 51\% respecto al año anterior, las que en total ascendieron a 4.893 miliones de dólares.

Utilidades de las Sociedades Anónimas (año 2000) ${ }^{4}$

\begin{tabular}{|l|c|}
\hline Sector Económico & Utilidades \\
\hline Forestal & 686.497 .700 .000 \\
\hline
\end{tabular}

3 En los últimos treinta años, la participación en el ingreso mundial del $20 \%$ más pobre de nuestro planeta se redujo de $2,3 \%$ a un $1,4 \%$; en contrapartida, el $20 \%$ más rico aumentó sus ingresos de $70 \%$ a $85 \%$. al extremo que si en 1996,358 personas supermillonarias - de las cuales cuatro son chilenas- acumulaban el $47 \%$ de la riqueza mundial, en el año 2000 sólo seis personas acumulaban el $57 \%$ de la riqueza mundial. Asi. si en ef año 1996 el número de pobres en América Latina bordeaba los 86 millones de personas $-18 \%$ de la población- se calcula que para el año 2005 esa cifra alcanzará los 176 miliones de personas viviendo en las mismas o peores condiciones. PROGRAMA DE ECONOMIA DEL TRABAJO (PET), La hoja de los Sindicatos, marzo (2001) 4 


\begin{tabular}{|l|r|}
\hline Electricidad & $411.366 .200 .000-$ \\
Bancos & $393.698 .900 .000-$ \\
Mineria Privada & $262.254 .400 .000-$ \\
Comercio & $143.159 .500 .000-$ \\
Servicios & $138.640 .700 .000-$ \\
Industria & $93.796 .000 .000-$ \\
Alimentos & $64.526 .000 .000-$ \\
Construcción & $37.718 .100 .000-$ \\
Transporte & $33.345 .100 .000-$ \\
Vitivinicola & $32.917 .300 .000-$ \\
AFP & $21.882 .500 .000-$ \\
Isapres & $11.554 .700 .000-$ \\
Textil & $1.992 .500 .000-$ \\
\hline Total: & $\mathbf{\$ 2 . 5 3 3 . 2 9 2 . 1 0 0 . 0 0 0 -}$ \\
\hline
\end{tabular}

Utilidades de los Principales Grupos Económicos (año 2000)

\begin{tabular}{|l|}
\hline Grupo Económico \\
\hline Angelini \\
Enersis \\
Luksic \\
\hline Total: \\
\hline
\end{tabular}

\begin{tabular}{|c|} 
Utilidades \\
$863.553 .900 .000-$ \\
$544.137 .400 .000-$ \\
$44.670 .100 .000-$ \\
$\$ 1.452 .361 .400 .000-$ \\
US $\$ 2.420 .602 .300-$
\end{tabular}

Sin duda los trabajadores han visto poco de estas exorbitantes ganancias. Al contrario, durante el año 2000, respecto del año 1999 se perdieron 58.000. puestos de trabajo y los salarios se vieron estancados 0 reducidos. En concreto, podemos decir que tanto a nivel mundial como nacional se ha instalando una sociedad marcada por dos velocidades, en donde sólo unos pocos tienen derecho a mucho y muchos derecho a muy poco, casi sólo a sobrevivir.

\section{B. El HORIZONTE dE LA DOCTRINA SOCIAL}

Una primera reacción ante las cifras que se acaban de exponer, es reiterar que hablar de la pobreza, no es hablar de problemas "materiales" sino de personas con rostros concretos: ancianos, adultos, jóvenes y niños, golpeados por la falta de los minimos necesarios para vivir dignamente (cfr Puebla 31-40). Son hombres y mujeres sufrientes, victimas de la injusticia de un sistema que los explota o, en el peor de los casos, los margina y los olvida. No son cifras, sino hermanos nuestros que claman al cielo por su liberación (cfr Medellin. Justicia, 1), y cuya presencia deberia golpear nuestra conciencia, indignarnos éticamente y movernos "a aceptar y asumir 
la causa de los pobres... como si fuera la causa misma de Cristo" (Puebla, Mensaje, 3).

En segundo lugar y desgraciadamente, como podemos deducir de las cifras, la pobreza sigue siendo una cuestión estructural que por lo mismo requiere para su solución un proyecto de sociedad alternativo al actual sistema global de libre mercado, claramente injusto y excluyente. Por ello propongo a continuación un horizonte más amplio, de sentido o valórico, que deberia animar nuestro compromiso como Iglesia con la superación de la pobreza.

\section{Frente a la indiferencia sobre la suerte de los pobres: no perder de vista la solidaridad como camino hacia la plenitud humana}

La acción politica del cristiano, y de todo hombre de buena voluntad, debe tender siempre a la búsqueda del Bien Común, "esto es, el conjunto de las condiciones de la vida social que hace posible a las asociaciones y a cada uno de sus miembros el logro más pleno y más fácil de la propia perfección" (GS 26). Ello exige la construcción de una sociedad basada en la solidaridad.

El ser solidario pertenece al ser mismo hombre, de modo que ambos aspectos se exigen. Nunca existirá, por tanto, un desarrollo integral del ser humano que no pase por el ser solidario. En efecto, sin una práctica de convivencia solidaria; es decir, sin la superación del solipsismo egoísta, el hombre no se realiza a si mismo. Las ideas de persona y solidaridad son correlativas; la persona crece y se desarrolia cuando pone a la obra el imperativo moral de la solidaridad con el otro, especialmente con las victimas de la injusticia $y$, por el contrario, el hombre se deshumaniza cuando cae en las redes de la indiferencia a su hermano: "Cada uno, sin excepción de Nadie, debe considerar al prójimo como otro yo, cuidando en primer lugar de su vida y de los medios necesarios para vivirla dignamente, no sea que imitemos a aquel rico que se despreocupó por completo del pobre Lázaro" (GS 28).

Según el Concilio, el camino que conduce a la justicia en el mundo pasa por el cambio de horizonte ético, en donde el individualismo queda superado por la solidaridad. En efecto, el individualismo conlleva una despreocupación frente a la realidad social, liegando incluso al desprecio de leyes, normativas u otros deberes en relación con la sociedad (cfr GS 30). Por el contrario, la persona que actúa movida por la solidaridad entregará su vida en el servicio a los demás, especialmente a los que sufren o ven sus derecho pasados a llevar. La persona solidaria encuentra el fundamento de su acción en el reconocimiento de la igual dignidad que todo hombre posee y cuya defensa se impone a la sociedad como una obligación de justicia.

Ahora bien, el compromiso solidario no debe entenderse como una mera y fácil acción asistencialista, sino que nos abre al compromiso político que tiende a la creación de estructuras sociales que reflejen las relaciones 
sociales de participación y comunión, excluyendo todo paternalismo. En consecuencia, el compromiso social de los cristianos. asi como de todos los hombres de buena voluntad, debe tener como horizonte el que las estructuras sociales, especialmente las económicas, estén al servicio de esa dignidad que todo hombre y mujer posee de modo inalienable. Una conducta solidaria, lejos de ser paternalista, es por una parte una invitación a la libertad y el protagonismo de todos los que componen el tejido social en vistas a la vida plena de cada uno de los miembros del cuerpo social; y por otra, es un compromiso profético de denuncia de todas las estructuras que obstaculizan la realización del Deseo de Dios de ver a cada uno de sus hijos e hijas alcanzar la madurez humana en el reconocimiento de la igualdad esencial entre todos los hombres: "Resulta escandaloso el hecho de las excesivas desigualdades económicas y sociales que se dan entre los miembros o pueblos de una misma familia humana. Son contrarias a la justicia social. a la equidad. a la dignidad de la persona humana y a la paz social e internacional' (GS 29).

\section{Frente a la idolatria de la propiedad privada y del lucro: no perder de vista la doctrina tradicional de la propiedad común de los bienes}

Mientras no existan canales adecuados que permitan y obligen a la redistribución de la riqueza será muy dificil la superación de esta injusticia radical de nuestra sociedad contemporánea. En esto la Iglesia ha tenido una postura bastante tradicional, aunque por muchos desconocida -de alli la importancia de incluir en la formación no sólo aspectos de doctrina teológica y sacramental, sino también social, de Doctrina Social-. Santo Tomás (cfr ST, II-II, q.66), por ejemplo, reconoce la Propiedad Común de los bienes como de origen divino y, por lo tanto, anterior a la propiedad privada que es de origen social, y cuya finalidad no es otra que velar por que se cumpla aquello de origen divino, es decir, que todos tengan io que necesitan para alcanzar su desarrollo pleno como seres humanos. La propiedad de los bienes es, para el Santo, un derecho natural de todo ser que llega a este mundo. Su privación es vista como injusticia y pecado. O sea, la propiedad privada sólo puede ser aceptada en cuanto contribuye a que todos accedan a los bienes necesarios para desarroliarse humanamente.

Santo Tomás hace la distinción entre bienes necesarios y bienes superfluos. Los primeros son aquellos sine qua non el hombre no alcanzaria su desarrollo pleno -alimento, vestido, habitación, educación, recreación. etc.- los segundo son aquellos de los cuales se puede prescindir por que no son necesarios para vivir humanamente. En caso de necesidad, estos últimos son de carácter común y pueden ser tomados por el pobre para satisfacer sus necesidades, sin que ello pueda ser considerado falta. Al contrario la Falta estaria en aquel que viendo la necesidad de su hermano no le entrega lo que le pertenece en justicia. 
Aqui, cobra su verdadera dimensión el hablar de Limosna. En efecto, para la doctrina de la Iglesia existe una limosna de justicia o precepto y otra de caridad (ST, II-II, q.32); la primera es aquella que se me impone como obligación de justicia, y corresponde a la redistribución de los bienes superfluos, luego no hay mérito en ella. La segunda, corresponde al despojo por amor de aquellos bienes que nos son necesarios en vistas al servicio del pobre. Esto es "dar hasta que duela", y no contentarse con una simple "ayudita" paternalista, que por lo general tiende más a liberar nuestra conciencia de sus verdaderas obligaciones. Para la Iglesia, "sean las que sean las formas de propiedad... jamás debe perderse de vista este destino universal de los bienes" (GS 69).

\section{Frente a la injusta distribución de las ganacias: no perder de vista la doctrina sobre el justo salario}

Saltándonos algunos siglos, resulta conveniente, retomar las enseñanzas de la Iglesia sobre el Justo Salario. El salario no es una dádiva que da el patrón a sus obreros, sino una obligación que nace de la común acción productiva que genera ganancias, las cuales deben ser distribuidas equitablemente entre todos aquellos que participaron en la generación de las mismas. Juan XXIII lo formula de la siguiente manera: "Ha de retribuirse al trabajador con un salario estblecido conforme a las normas de la justicia y que, por lo tanto, según las posibiliadades de la empresa, le permita tanto a él como a su familia mantener un género de vida adecuado a la dignidad del hombre" (PT 20; cfr Pablo VI, OA 14 y, el mismo Concilio Vaticano II en GS $67)$.

En esta misma dirección el papa Juan Pablo II afirma que: "el problema clave de la ética social es el de la justa remuneración por el trabajo realizado" (LE 19²). En esto el papa es consecuente con su postura de mirar la economía desde su "subjetividad", es decir, desde el sujeto de la misma, y no desde su "objetividad", es decir, sólo como una actividad que apunte a la obtención de bienes y de lucro. La Economia tiene ante todo un rol social y humanizante y su valor debe ser medido "con el metro de la dignidad del sujeto mismo del trabajo. o sea de la persona, del hombre que lo realiza" (LE $6)$.

Para el papa el salario es el simbolo monetario y jurídico de la justicia social: "la justicia de un sistema socio-económico y. en todo caso, su justo funcionamiento merecen. en definitiva, ser valorados según el modo como se remunera justamente el trabajo humano dentro de tal sistema... De aqui que precisamente el salario justo se convierta en todo caso en la verificación concreta de la justicia, de todo el sistema socio-económico $y$, de todos modos, de su justo funcionamiento. No es esta la única verificación, pero es particularmente importante, y es en cierto sentido la verificación clave" (LE 19b). La razón para dar tal importancia al salario es que se le reconoce como "una via concreta a través de la cual la gran mayoria de los hombres 
puede acceder a los bienes que están destinados al uso comín: tanto a los bienes de la naturaleza como los que son fruto de la produccion" (LE 19).

En este punto se hace imprescindible el papel regulador del Estado, especialmente en vistas a la protección de los justos derechos de los trabajadores. El estado no puede renunciar a jugar un rol determinante como "empresario indirecto", esto es, entregando las normas dentro de las cuales se deben dar las relaciones laborales. El papa Juan Pablo II, dice en su ya citada enciclica LE que "la distinción entre empresario directo e indirecto parece ser muy importante en consideración de la organización real del trabajo y de la posibilidad de instaurar relaciones justas o injustas en el sector del trabajo... como empresario indirecto se deben entender muchos factores diferenciados... que ejercen un determinado influjo sobre el modo en que se da forma bien sea al contrato de trabajo, bien sea. en consecuencia, a las relaciones más o menos justas en el trabajo humano" (16). Aunque "indirecto" se trata aqui de una verdadera responsabilidad, condicionando el espacio del propio empresario directo y del trabajador en sus relaciones reciprocas.

\section{Frente al desánimo por la falta de proyectos alternativos de sociedad: no perder de vista la eficacia en el tiempo de un trabajo constante de formación en la base}

Me parece, para concluir, que como Iglesia deberiamos ser capaces de generar un movimiento formativo en vistas a la acción politica práctica de los que nos llamamos cristianos, sin exciuir, por supuesto, a todos aquellos hombres y mujeres que comparten con nosotros los mismos anhelos de justicia y solidaridad. Se trata de asumir una práctica formativa y efectiva en favor de los pobres teniendo como horizonte la utopía del Reino, es decir, el deseo de Dios de ver a todo hombre y a toda mujer viviendo en plenitud. Se trata de generar desde la base una práctica participativa y solidaria que tenga a los pobres como protagonistas, como sujetos y no como objetos, de tal modo que se evite toda forma de paternalismo ya sea económico ("tecnócratas") o politico ("vanguardias conductoras"), asi como la manipulación ideológica o religiosa de los pobres.

Un proceso formativo al interior de las comunidades cristianas que lleve a superar el inmobilismo o la indiferencia de muchos cristianos por la cosa politica así como la superación de las soluciones de corte meramente asistencialista, para concentrarse en la búsqueda de una verdadera "caridad politica" o "santidad politica" que no pierda de vista el horizonte estructural de la situación actual y que, por lo mismo, no se contente con pequeñas reformas al sistema, sino que apunte a la transformación de este mundo según los valores del evangelio.

Dicho proceso formativo deberia apuntar a la generación de comunidades cristianas adultas, comprometidas proféticamente con la superación de la pobreza y la marginación en vistas a la realización aqui y 
ahora del reino de Dios, que es vida en abundancia para todos. Para ello la formación deberia asumir ciertos presupuestos mínimos:

- Formar comunidades cristianas preocupadas por conocer la pobreza y sus causas, discerniendo alli iniciativas concretas en beneficio de un proyecto alternativo al actual.

- Formar comunidades cristianas que adopten una posición política, lúcida y eficaz, al estilo de los profetas, capaz de aliarse con sectores que favorezcan la liberación de los pobres a través de prácticas solidarias alternativas y de métodos no violentos.

- Formar comunidades cristianas que se distancien proféticamente en sus prácticas, tanto de los que oprimen como de los que manipulan a los pobres, pasando del paternalismo a una acción en donde los pobres sean sujetos y protagonistas de su liberación. 
